\section{Las artesanías Zenú: transformaciones y continuidades como parte de diversas estrategias artesanales}

Paola Trocha*

\begin{abstract}
Resumen: En el ámbito de la producción artesanal, existen muchas investigaciones y estudios en referencia a las artesanías y a su modalidad de producción en las distintas comunidades. El oficio artesanal ha sido estudiado bajo diversas perspectivas, desde lo antropológico, desde su modalidad productiva, desde su estructuración y división del trabajo dentro del núcleo familiar, desde las innovaciones de sus técnicas, hasta su comercialización. Este artículo estudia la producción artesanal desde la perspectiva de los flujos culturales y el dinamismo constante de la actualidad y su influencia en las nuevas artesanías, específicamente aquellas que son combinadas con otras técnicas originarias de distintas comunidades artesanas. Esta nueva tipología de artesanías surgió recientemente en Colombia, bajo las manos artesanas de la etnia Zenú en el departamento de Córdoba. Las condiciones que favorecieron su elaboración, requieren ser estudiadas y evaluadas desde las perspectiva de los distintos actores activos en el campo artesanal; considerándose las cualidades intangibles que aportan los aspectos tradicionales y los valores culturales a la producción. El análisis de estas consideraciones, entendidas como parte de procesos sociales dinámicos, se investiga bajo la perspectiva del desarrollo de las artesanías, cómo las distintas innovaciones técnicas, las nuevas demandas surgidas en los tiempos modernos y su posicionamiento en el mercado, desembocan en nuevas estrategias comerciales y producciones de artesanías combinadas con técnicas de distintas comunidades artesanales.
\end{abstract}

Palabras clave: Campo social - Pueblos originarios - Producción Artesanal - Diseño Identidad Cultural - Comercialización artesanal.

[Resúmenes en inglés y portugués en las páginas 123 - 124]

${ }^{(*)}$ Paola Trocha. Diseñadora Industrial (Universidad del Norte. Barranquilla, Colombia). Magíster en Gestión del Diseño (Universidad de Palermo, Buenos Aires, Argentina). Tesis de Honor (UP). Trabajos de investigación basados en la compleja relación entre diseño y artesanía en dos líneas de Investigación de la UP: Investigar en Diseño y Diseño en perspectiva. Partícipe de distintos congresos y coloquios. Actividad en la Docencia como asistente académica en el Seminario de Metodología de la Investigación de la Maestría en Gestión del Diseño DC (UP). 


\section{Introducción}

El presente trabajo analiza de forma específica los productos artesanales elaborados por la etnia Zenú en Córdoba, Colombia. El objetivo es investigar bajo la perspectiva del desarrollo de las artesanías, cómo las distintas innovaciones técnicas, las nuevas demandas surgidas en los tiempos modernos y su posicionamiento en el mercado, desembocan en nuevas estrategias comerciales y producciones de artesanías combinadas con técnicas de distintas comunidades artesanales. Para comprender esto, es necesario abordar el concepto de artesanía como un proceso complejo, que obliga no sólo a ver a las piezas artesanales como objetos desarrollados bajo técnicas tradicionales y ancestrales de una comunidad en particular, sino a analizarlas como objetos que no son ajenos a los cambios que ocurren en el entorno al cual pertenecen y que además, son 1 columna vertebral de la producción artesanal, porque sobre ellas se trabajan nuevas propuestas y nuevos cambios para dar lugar a nuevas estrategias comerciales que garanticen la prevalencia en el mercado de sus hacedores.

El estudio de campo en el que se soporta este artículo se desarrolló en la etnia Zenú asentada en el municipio de Tuchín y en el resguardo de San Andrés de Sotavento en el departamento de Córdoba, Colombia durante un período entre 2016/2017. Se realizaron entrevistas en profundidad a artesanos de la comunidad Zenú, diseñadores vinculados a la producción artesanal, funcionarios de Artesanías de Colombia, y a comercializadores de artesanías elaboradas en caña flecha; para abordar y tener en cuenta las distintas perspectivas que tienen estos actores dentro de esta producción artesanal.

\section{Etnia Zenú: un abordaje artesanal en la actualidad}

Los zenúes son el tercer grupo indígena más numeroso de Colombia (DANE 1 , 2005). Están asentados principalmente en la región de las sabanas del caribe colombiano entre los departamentos de Córdoba y Sucre, de los cuáles la mayor parte de la población vive en zonas rurales, como los municipios de San Andrés de Sotavento, Tuchín, Sampués, Chinú, Sincelejo, y Palmito (ver figura 1).

En la actualidad están organizados bajo la figura territorial del resguardo. Esta categoría surgió en la época colonial pero es considerada una forma de organización del territorio indígena en el país y está amparada bajo ciertas condiciones establecidas en la constitución política de Colombia de 1991. Gran parte del resguardo se halla en los territorios del departamento de Córdoba, habitando apenas una pequeña parte de lo que fue su territorio ancestral. Esto se debe a que en la región se encuentran inmensas porciones de tierras dedicadas a la ganadería que pertenecen a pocos hacendados. Lamentablemente, desde el descubrimiento en el siglo XVI, los indígenas de este grupo han sufrido de expropiación, exterminio y despojo, viéndose reducidos y hacinados a una pequeña parte del territorio (Larraín, 2014).

Si bien son reconocidos, por su sistema de irrigación de aguas, por la orfebrería y cerámica precolombina, incluso algunas de sus piezas son expuestas en varios museos del país, el panorama actual que viven los zenúes es muy distinto. Entre esta etnia ya no existe la orfebrería, hay poca cerámica y los prodigiosos canales ya no existen. Su territorio ha sido reducido, el agua es un recurso natural escaso, y el oro fue extraído y saqueado a través de 
los siglos. Hoy, sus principales actividades productivas son: la cría de animales domésticos y el cultivo de tubérculos con fines de autoconsumo, y por último, se encuentra la artesanía en caña flecha.

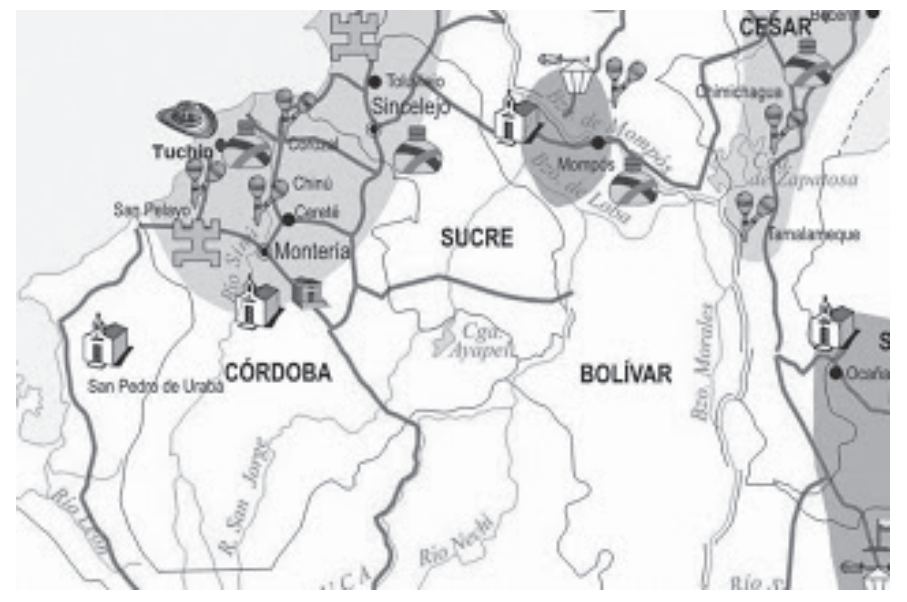

Figura 1. Territorio indígena Zenú. Fuente: http://famituchincordoba.blogspot.com.ar/

Según fuentes del estudio realizado por el Sistema de Información Estadístico de la Actividad Artesanal, en adelante SIEAA, realizado en noviembre de 2015, la actividad artesanal y la agricultura son fuentes de sustento económico, siendo la primera la principal (ver tabla 1 y figura 2).

Tabla 1.

Artesanías como fuente principal de ingresos del hogar. (Tuchín)

\begin{tabular}{ccc}
\hline & Datos & \\
\hline $\mathrm{Si}$ & No & Base \\
$76 \%$ & $24 \%$ & 49 \\
\hline
\end{tabular}

Nota. Recuperado de "Diagnóstico del sector artesanal y las particularidades regionales en Colombia, artesanías en barro de Chamba, filigrana y caña flecha", por Rafael Monserrate; Daniel Serrano, 2016,p.6.

Tabla 1. Fuente: Monserrate y Serrano (2016, p.6) 


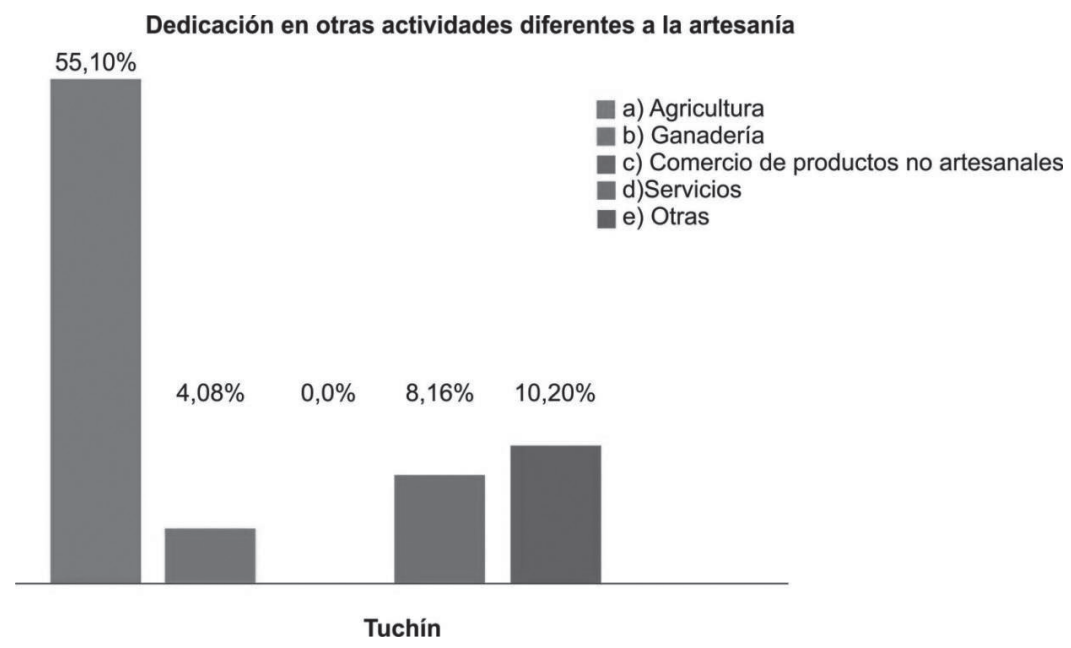

Figura 2. Dedicación en otras actividades diferentes a la artesanía.

Fuente: Monserrate y Serrano (2016, p.11)

Para los zenúes la actividad artesanal está arraigada a su vida cotidiana, a través del tejido representan su cultura y mantienen vivo su legado. "Tejer es un legado que nos han dejado nuestros antepasados, ya que por medio de este trenzado nosotros estamos sobreviviendo" L. Flórez (en comunicación personal, 19 de julio, 2016). A diferencia de otras actividades económicas alternas, el oficio artesanal es desempeñado por todos los miembros de la familia, afianzando los lazos entre ellos, perfeccionando las destrezas individuales de cada miembro y siendo fuente de orgullo y de satisfacción personal.

Hasta esta instancia, se ha esbozado de forma general su contexto histórico y un tanto más detallado su contexto actual. Los zenúes a lo largo de su historia han sufrido grandes cambios culturales y tradicionales, pero al mismo tiempo es un grupo con un importante reconocimiento y trayectoria en el país, y esto es gracia a las acciones y decisiones que toman sus principales agentes (líderes, docentes, indígenas, e instituciones), que procuran luchar por sus reivindicaciones en un escenario tan vulnerable como la pobreza.

\section{Artesanías en caña flecha}

Existen dos clases de artesanos Zenú. Unos se dedican exclusivamente a trenzar la caña flecha y otros se dedican a comprar la trenza ya elaborada para armar distintos productos. En el primer caso, el inicio del proceso comienza con la elección de la caña en los campos de cultivos. La palma costera, martinera y criolla, conforman la variedad de palmas de caña flecha que van de la más baja calidad hasta la más alta, respectivamente. Luego de la 
elección de la fibra, el proceso continúa con el corte, raspado y ripiado de la misma. A su vez, se limpia y se seleccionan las fibras que van para el teñido, que luego se deben secar en un lapso de 24 a 48 horas según sean las condiciones del clima. Finalizado todos estos pasos, se procede a tejer la trenza, la cual se vende por metros.

En el segundo caso, el proceso del artesano es más corto ya que compra los metros de trenza hechos. De allí se dedica a manufacturar los productos que desea vender y elaborar los moldes y matrices del nuevo producto que desee hacer. En ambos casos la regulación de calidad depende del compromiso personal. El artesano Reinel Mendoza cuida el proceso desde la elección de la palma hasta su completa terminación. Esto implica que debe prestar atención en los cuatro procesos posteriores: trenzado, que debe ser uniforme y estructurado; teñido, cuyo color debe ser fuerte y sólido; costura, que debe ser lineal, continua y lo más invisible posible (elección de color del hilo); y el armado, donde se evalúa la estructura y forma final del producto. Esta rigurosa inspección de calidad se refleja en un buen producto, el cual se convierte en la firma y en el posterior renombre que su artesano pueda obtener, virtud que les abre caminos a solidificar posibles relaciones con clientes y comerciantes.

\section{Productos tradicionales y nuevos productos}

En el marco productivo y comercial artesanal, se distinguen los productos tradicionales, aquellos que conservan los parámetros ancestrales, de aquellos nuevos productos que responden al mercado. Las artesanías en caña flecha son destacadas y reconocidas en el territorio colombiano porque dentro de su variedad se encuentra el sombrero vueltiao símbolo cultural del país. Esta distinción ha promovido que muchos profesionales de diversas disciplinas se hayan interesado en estudiar un poco la cultura zenú. Los estudios en territorio Zenú han concentrado esfuerzos para aportar al mejoramiento de calidad de vida de los indígenas. Sin embargo, la confluencia e inserción de agentes externos al campo artesanal Zenú, han derivado no sólo en cambios socio-culturales, sino proyectuales a nivel de concepción, desarrollo, comercialización y consumo de las artesanías.

En efecto, la etnia Zenú ha direccionado sus esfuerzos para crear estrategias afines al mercado, ajustando pautas a nivel de diseño, producción y promoción. En consecuencia, los zenúes no sólo se destacan por el sombrero vueltiao, sino por la gran diversidad de productos que ofrecen. Reinel Mendoza manifiesta que entre la década de los años 60 y 70 , la etnia Zenú empezó a ampliar su catálogo de productos y a mejorar sus técnicas (en Comunicación personal, 04 de agosto, 2016). Comenzaron a producir bolsos, billeteras, monederos, elementos de bisutería, calzado, e incluso elaboran elementos portadores de artículos tecnológicos, elementos de decoración de hogar, y telares para tapizar mobiliarios o cuadros. Lo anterior evidencia una clara influencia del mercado en los productos que ellos elaboran. Su interés por mantenerse activos en el mercado, lleva a que concentren esfuerzos para plantear innovaciones en sus productos y tener algo nuevo que mostrar al mercado.

Gracias a esta persistencia por la búsqueda de la innovación, en la producción artesanal Zenú se evidencian productos elaborados con caña flecha combinados con otra técni- 
ca artesanal. Es decir, en una pieza de artesanía se combinan dos técnicas originarias de distinta comunidades artesanas. En virtud a la comprensión de la causa de esta situación particular en la producción Zenú, se hace referencia el trabajo de García Canclini (1999) y su interés por explicar los conflictos multiculturales de la globalización en su libro "Consumidores y Ciudadanos".

"Hay que examinar lo que la globalización, el mercado y el consumo tienen de cultura. Nada de esto existe, o se transforma, sino porque los hombres nos relacionamos y construimos significados en sociedad. Aunque parezca trivial evocar este principio, demasiado a menudo los problemas del consumo y el mercado se plantean sólo como asuntos de eficiencia comercial, y la globalización como la manera de llegar rápido a más ventas." (García Canclini, 1999, p. 18)

En definitiva, el dinamismo cambiante, provocado en gran parte por la confluencia y relaciones entre agentes internos y externos al campo artesanal, propician cambios que construyen nuevos parámetros en diversos aspectos. Las líneas de marroquinería, decoración y de elementos de protección para productos tecnológicos, constituyen en gran parte el portafolio de productos de los artesanos Zenú, que marcados por la tensión de permanencia mercantil, los motiva siempre a incursionar nuevas propuestas para sus productos.

\section{Interculturalidad en el contexto de las artesanías y los caminos hacia la diversidad cultural}

El ambiente de comercialización permite que la comunidad artesana se familiarice y se vincule con factores como migración, modernización, comportamiento de los mercados nacionales e internacionales, responsables del dinamismo y los flujos culturales presentes en estos tiempos; factores que sin duda influencian el diseño y producción de las artesanías contemporáneas. A partir de las nacientes naciones modernas, los intereses y las perspectivas tanto de campesinos como de indígenas trascendieron conforme a la extensa difusión del mundo. Sin embargo, esto no fue causante de disolución de una comunidad étnica o nacional, por el contrario, "fue una apertura de las fronteras geográficas de cada sociedad para incorporar bienes materiales y simbólicos a de las demás” (García Canclini, 1995, p. 15). Este dinamismo se destaca como un contexto favorable para la ampliación de los mercados, ya que permite que los productos y las personas se desplacen por amplias distancias, lo que Mazziotti y Borda (1997) lo llaman como la práctica de "pensar global, actuar local" como vía para insertarse en nuevos mercados (en Bayardo y Lacarrieu, 1997, p.15).

En este movimiento globalizador la multiculturalidad está presente, no como un proceso simple ni exento de tensiones. En este sentido, la globalización abre las puertas a una interacción de varias dimensiones, entre ellas, las económicas y culturales. (García Canclini, 1995) En la dimensión económica, analizada en el contexto artesanal, se evidencia el impulso de las artesanías al ámbito internacional. A consecuencia de esto, algunas piezas artesanales actuales se desvinculan de esa fidelidad que tiene una pieza artesanal ancestral, 
ya que son producidas en respuesta a un mercado global. Por su parte, en la dimensión cultural, cada comunidad étnica o nacional intrínseca en el dinamismo se enriquece por los cambios propios de una sociedad sumergida en flujos culturales y de información, los cuales terminan difuminando los límites de las identidades locales, estableciéndose fusiones entre diversas culturas.

Es preciso considerar que las facultades autónomas en la toma de decisiones para adoptar nuevas formas de hacer y de implementar cambios que caracterizan a algunas comunidades indígenas posmodernas, son atributos que no se pueden evaluar en términos de autenticidad sino comprendidas en congruencia con el contexto de la época. El concepto de aboriginalidad expuesto por Beckett (1988), se fundamenta en "las formas mediante las cuales los aborígenes seleccionan su experiencia y herencia cultural para comunicar un sentido de identidad a su gente joven" (p.1). Desde esta perspectiva, no es intención del autor determinar quién es aborigen o quién no lo es; o determinarlo en términos de autenticidad. Por el contrario, el autor pretende explicar cómo los descendientes o población actual de determinado grupo han mantenido y reproducido la noción de aboriginalidad. En este sentido, Beckett sostiene que la vitalidad aborigen reside, no en las características particulares de cada grupo, sino en la fuerza de su continuidad. Por ello, el concepto es una construcción cultural. (Beckett, 1988)

Bajo la aboriginalidad y la etnicidad se suele determinar la identidad. Sin embargo, Barth (1976) plantea la identidad en términos relacionales. Para ello, propone un enfoque más dinámico repensando el concepto de grupos étnicos y su permanencia entre los límites de sus fronteras. El autor discute las concepciones de que un grupo étnico se define por una cultura, costumbres, o vestimenta particular. Asimismo, no comparte las opiniones que consideran que la conservación cultural depende del aislamiento geográfico y social. Es decir, sus argumentos rompen cualquier noción clásica de la antropología de considerarlos como grupos aislados. Barth (1976) plantea dos categorías en las cuales operan estos grupos. Estas son: la autoadscripción y la adscripción por los otros. Esta doble categorización define cómo los integrantes del grupo se identifican y se posicionan frente al mundo (autoadscripción, interior del grupo); y también cuáles son las imágenes o referencias que tienen los demás grupos sobre uno en particular (adscripción, exterior del grupo). Para el autor, los límites entre grupos étnicos se fundamentan en la interacción interna y externa, por tanto sostiene que a mayor interacción, mayor será la construcción de estos límites. Esto sostiene la idea central que las fronteras entre los grupos étnicos son dinámicas, ya que constantemente las personas se están movilizando. Existen instancias que han favorecido la interlocución entre pueblos vecinos. Por un lado, se encuentran la confluencia de turistas, clientes, comerciantes, entre otros agentes externos; y por el otro, están los encuentros nacionales y regionales, bajo la figura de ferias o exposiciones donde asisten participantes artesanos oriundos de distintos pueblos indígenas. Son en estos espacios donde se compaginan el intercambio de artículos, de conocimientos y de técnicas entre los distintos grupos. "Yo tuve la experiencia de que le di un sombrero a un amigo de la Guajira, y él me dio una mochila” I. García (en comunicación personal, 04 de junio, 2016) Para García Canclini (1995), existen marcadas diferencias étnicas, regionales y nacionales entre los distintos países, pero que no se convierten en un obstáculo que impida su articu- 
lación en estos tiempos de globalización. Para el autor, "La heterogeneidad multitemporal y multicultural no es un obstáculo a eliminar, sino un dato básico en cualquier programa de desarrollo e integración" (García Canclini, 1995, p. 150). Lo antedicho enaltece el papel positivo de las diversidades culturales, las técnicas de producción y los hábitos de consumo tradicionales como alternativa de desarrollo. Sin embargo, es necesario referenciar el alcance de la cultura en este dinamismo.

Para comprender las complejas situaciones presentes en los distintos grupos étnicos es necesario abandonar las antiguas concepciones estáticas de cultura, y empezar a entenderlas bajo el dinamismo que las caracteriza. En palabras de Jackson (1995), "La cultura no es el legado primordial del pasado; la cultura no es estática, un sistema homogéneo sobre el cual se impone el cambio. Más bien, las culturas son sistemas cuyos fundamentos están caracterizados por el dinamismo, la negociación y la contienda" ( p. 20).

El dinamismo, la negociación y la contienda conforman los entes motores que ocasionaron la articulación de distintas técnicas originarias en la producción artesanal Zenú. El dinamismo propició las eventuales confluencias de distintas culturas, lo cual abrió las puertas para intercambios e integraciones de técnicas, y con ella negociaciones entre las partes para hacer frente a la contienda por la permanencia en el mercado artesanal. En otras palabras, gracias a la persistencia por la búsqueda de nuevas propuestas para los productos, los indígenas zenúes consideraron anexar otras técnicas originarias en sus artesanías como componente innovador que permitiera permanecer vigentes en el mercado. En este sentido, se evidencia como dos culturas o comunidades distintas conviven y se construyen en la imparcialidad para generar estrategias comerciales que los mantengan vigentes en la lucha por la prevalencia mercantil.

Lo anterior, conforma la base para la definición del concepto de interculturalidad. Según Alavez (2014), la interculturalidad parte de la base del contacto o interacción entre culturas distintas, generando un espacio de mutuo entendimiento para comprender lo propio en relación con lo extraño. Así, el proceso de asimilar lo extraño debe ser considerado no como amenaza a la cultura propia, sino como un elemento enriquecedor. En referencia a esto, culturalmente el indígena tiene la costumbre de hacer trueque, es decir, cambiar una cosa por otra I. García (en comunicación personal, 04 de junio, 2016). Por tanto, es la oportunidad que favorece al análisis de una técnica foránea y su posibilidad de integrarla con las técnicas locales. Lo anterior, llevado al contexto artesanal, particularmente a la comunidad Zenú, confirma que son las relaciones entre los distintos agentes involucrados -sean con artesanos, comerciantes, diseñadores- las responsables de las modificaciones que se presentan a nivel social, cultural, e incluso a nivel proyectual y conceptual en el diseño de las artesanías.

En este sentido, las marcadas diferencias entre culturas siguen existiendo, y la confluencia entre ellas no significa que alguna se suprima, por el contrario, se articulan. La heterogeneidad o las múltiples culturas no son un obstáculo que deba eliminarse para construir una globalización uniforme, son un componente básico para seguir desarrollando más diversidad, y generando nuevas condiciones de producción artesanal, como es el caso de estudio de la etnia Zenú. Desde esta perspectiva, este trabajo aborda las incursiones no desde la mirada del impedimento o la pérdida del desarrollo cultural, sino en términos de 
analizar el dinamismo de estos tiempos como promotor de su construcción. De allí que se consideren a las artesanías como manifestaciones culturales, y a su vez se tome a la cultura como una yuxtaposición de diversas cuestiones fundamentadas en circunstancias particulares a nivel económico y político, las cuales son condicionantes para su cimentación.

\section{Artesanía, la permanente tensión por la permanencia y la innovación}

En la actualidad, el capitalismo ya está inmerso en la actividad artesanal y se hace necesario considerar a las artesanías como productos que se han insertado en el sistema económico. Benedetti (2014) sostiene que aquellas nociones conceptuales que definen a las artesanías según su forma de producir, como objeto o producto de representación, deben ser superadas para empezar a considerarlas como una nueva forma de elaboración cuyo objetivo fundamental es situar la producción artesanal dentro del marco capitalista (Benedetti, 2014:22). Citando a Lauer, la autora sostiene que:

"Las artesanías no remiten a un fenómeno homogéneo, coherente y unificado, sino a un complejo contradictorio de objetos y procesos. [...] la producción artesanal no pasa a existir bajo el capitalismo (como si fuera un nuevo territorio geográfico que se pudiera penetrar físicamente), sino que el capitalismo empieza a existir en ella, a reproducirse en su interior" (Lauer en Benedetti: 22)

Bajo esta línea, Rotman (2007) en su trabajo realizado en la comunidad Mapuche, enfatiza que se observa una menor producción de artículos destinados al uso doméstico o cotidiano, que mantengan formatos y diseños ancestrales. Por el contrario, cada vez y en mayor medida, se encuentran artesanías elaboradas para el mercado turístico, cuyos diseños responden a patrones y uso de la sociedad global. Estas cuestiones están relacionadas al interés y preferencia de los artesanos en manufacturar productos para los turistas. En este sentido, el proceso productivo observa una tensión entre la permanencia y la innovación (Rotman, 2007) que implica para los productores modificaciones en el diseño, continuidad en el estudio de materia prima y profundización en el conocimiento de sus técnicas. En consecuencia, comenzaron a generarse modificaciones alrededor de las artesanías: las formas de organización del trabajo, las formas de producción e incluso los productos artesanales resultantes. Lo antedicho, implica tener en cuenta todo este proceso y considerar a la comercialización como un aspecto importante en la economía artesanal, ya que integra las instancias de la producción como las de circulación y consumo. Las pautas de producción y comercialización Zenú no difieren de estas circunstancias anteriormente mencionadas. En efecto, su producción de artesanías no responde a fines cotidianos o de autoconsumo, sino a fines comerciales, por tanto todos los ajustes que los artesanos han hecho con el pasar del tiempo a sus procesos internos, han sido promovidos para responder a las exigencias del mercado con el objetivo de seguir aún vigentes.

Las artesanías Zenú evidencian cómo la diversidad cultural y la cohesión social han sido utilizadas como nuevas alternativas de desarrollo y como estrategia de prevalencia comer- 
cial. Entre ellas se encuentran aquellos productos que mezclan la caña flecha con otros materiales como cuero y sintéticos (ver figura 3), cuya intención es asemejar estas artesanías a los productos que regularmente se venden en el mercado. Estas pautas de inserción de nuevos materiales fueron herramientas que les dieron, por un lado, profesionales en el diseño que han venido trabajando con los artesanos. Y, por el otro, responden a las exigencias que les hacen sus clientes o intermediarios.

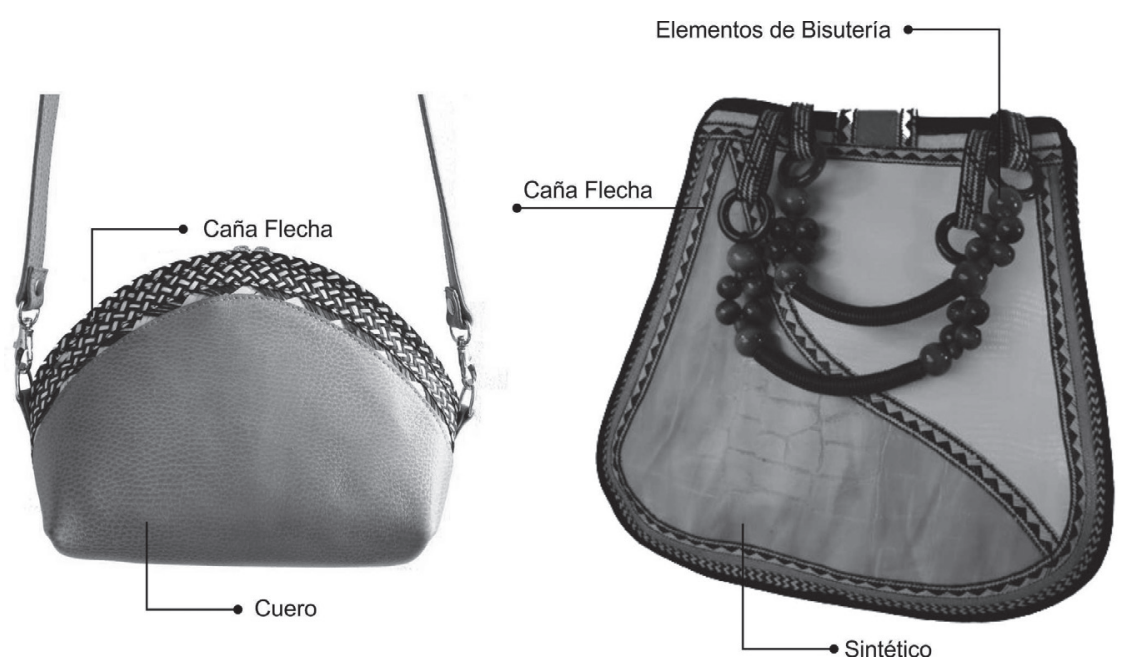

Figura 3. Artesanías en caña flecha y cuero. Elaboración propia

La combinación de técnicas artesanales originarias de distintas comunidades, dan cuenta que la confluencia de distintos actores: profesionales, entidades gubernamentales, entidades sin ánimo de lucro, comerciantes, etc.; conjugados con las habilidades y destrezas de los artesanos, inmersos en una sociedad dinámica, englobante y consumista, han provocado diversos cambios a nivel productivo que forman parte de las mutaciones de las costumbres. Para Ledesma (2005), estas situaciones se circunscriben dentro del marketing intercultural. El autor sostiene que este fenómeno de diversidad y de interculturalidad propicia la formación de un sistema en el cual se reconozcan, se acepten y se validen las distintas maneras de hacer respecto a las propias. De esta forma, el marketing intercultural propone "maximizar las utilidades y obtener la satisfacción total del cliente, todo mediante una buena mezcla comercial" (Ledesma, 2005: 82) y afianzar el flujo de productos y servicios que ofrece una cultura determinada hacia otras culturas foráneas, considerándose al dinamismo cultural como factor constituyente e influyente en las nuevas formas de concepción de productos artesanales. 
Para García Canclini (1995) se hace necesario estudiar lo que el mercado y el consumo tienen de cultura, en el sentido de que ninguno de estos dos conceptos tuviera lugar si no existiera la dinámica y los flujos culturales generados por la interacción de personas y la construcción de nuevos significados en la sociedad. Bajo esta perspectiva, es común dejar de lado aspectos importantes que forman parte en todo este proceso mercantil, como la relación entre el artesano y el comerciante que resalta Appadurai (1991). Para el autor, esta relación involucra la capacidad de suministro de productos que posee el artesano frente a la capacidad y el manejo de información que tenga el comerciante de estas artesanías. Sin embargo, es importante evaluar el "estatus cambiante" tanto del artesano como del comerciante dentro de sus respectivas sociedades. Ambos actores se encuentran inmersos en una dinámica cultural cambiante, por ende la negociación entablada por ellos en términos comerciales, se rige por un complejo sistema social del cual el artesano forma parte, y por un mercado al cual el comerciante debe cultivar. Las relaciones comerciales Zenú suelen ser tríadicas, es decir tres actores con perfil distinto para vender determinada pieza artesanal, artesano-intermediario-comerciante. Desde esta perspectiva, se complica la comunicación entre las partes ya que son más actores los involucrados y vuelve el análisis más complejo.

En otras palabras, la comunicación que existe entre el intermediario y el artesano es netamente comercial, donde éste le pide determinada cantidad y tipo de modelo del producto que requiere para cumplir con la venta de su comerciante. Es decir, no existe una retroalimentación o sugerencias por parte de él que pueda enriquecer al artesano. Este es el punto en el cual Appadurai (1991), lo considera un problema en la medida en que la popularidad de las artesanías crezca, ya que debe existir una sólida comunicación entre las partes que asegure que estén negociando mercancías comprendidas en un mismo marco social.

Esta perspectiva amplía el campo de investigación al no solo considerar el proceso mercantil de los productos artesanales sólo como aspectos meramente económicos y comerciales, sino también a tener en cuenta a los actores involucrados en estas negociaciones, que como sujetos inmersos en una sociedad cambiante son vulnerables a los cambios de construcción social y cultural que afectan al proceso de comercialización de las artesanías. En palabras de Rotman (2007),

"Entendemos que los procesos a los cuales nos referimos, son factibles de ser comprendidos desde una perspectiva no sustancialista, que entiende que las identidades étnicas se conforman a partir de procesos históricos específicos, que incluyen fenómenos de permanencia y de cambio y que en tal contexto las producciones culturales son dinámicas y se expresan en ellas las características de las condiciones de vida de los pueblos originarios, así como las problemáticas y tensiones implícitas en su relacionamiento con la sociedad global"(Rotman, 2007:62)

De acuerdo a lo anterior, este trabajo considera a estas interacciones y variaciones productivas como respuesta de los indígenas a las tensiones por la permanencia e innovación, mismas que no carecen de rasgos o características culturales esencialistas que las puedan condenar como productos no auténticos o genuinos, sino como parte de procesos que son dinámicos y cambiantes que responde a un contexto específico. 


\section{Artesanías combinadas Zenú: Análisis morfológico, conceptual y comercial}

Dentro del marco artesanal Zenú, el contexto de combinación de técnicas autóctonas se produjo bajo un intercambio de elementos culturales propios y ajenos, donde los zenúes tomaron la decisión de implementar una técnica ajena a sus productos. Por consiguiente, hay una prevalencia de cultura autónoma, al tomar decisiones sobre su propia técnica ancestral en combinación con otra técnica foránea. Dentro de la variedad de técnicas foráneas que ellos más han adoptado son la mola de los indígenas Kuna y Emberas; seguido de las técnicas de la palma de iraca, elaboradas por los artesanos del municipio de Usiacurí en el departamento del Atlántico, y las técnicas artesanales de los indígenas Wayuú en el departamento de la Guajira (Ver figura 4)

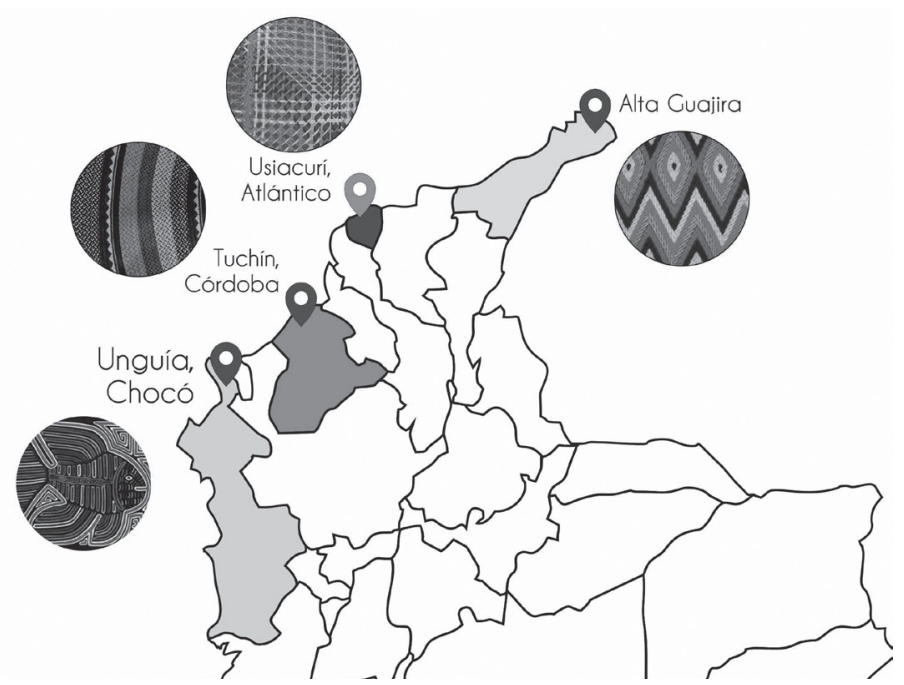

Figura 4. Algunas técnicas/texturas del caribe colombiano. Fuente elaboración propia

Las concurrencias y los contactos entre estos grupos se deben a las cercanías de los asentamientos indígenas como sucede en el caso de los Kuna y los Emberas. Asimismo, hay facilidad en conseguir los otros elementos artesanales de departamentos alejados a través de contactos ya establecidos o por medio de intermediarios que se encargan de llevarlos de una comunidad a otra; como sucede con la artesana Maribel Medina, quien desde la ciudad de Cartagena ya tiene establecida una relación comercial con dos intermediarios: uno que le provee la caña flecha, y otro que le provee la palma de iraca o la mola. Algunos de los ejemplos de estos objetos artesanales son los siguientes. (Ver figura 5) 

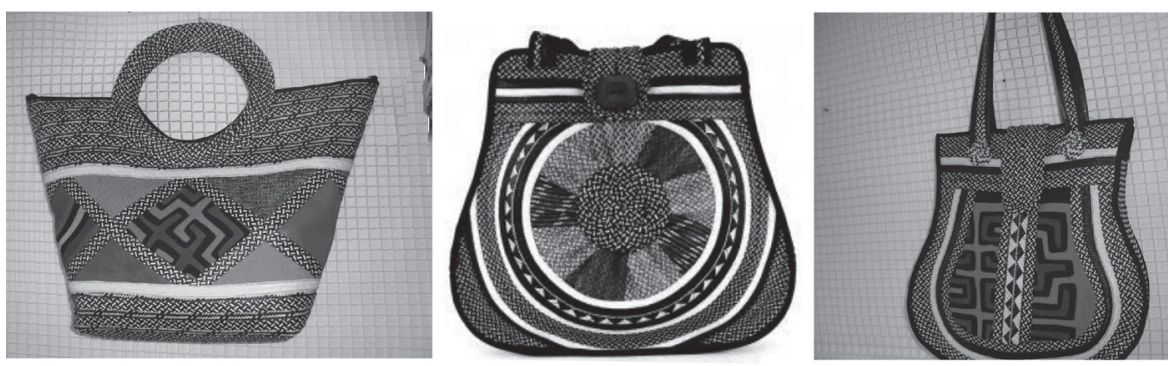

Figura 5. Ejemplos de productos artesanales combinados en técnicas. Fuente. Maribel Medina

La mezcla de técnicas implica un control cultural (Bonfil Batalla, 1991) de ambas partes de las comunidades permutables. Por parte de los zenúes, su decisión radica en realizar cambios a su elemento cultural (propio) de categoría material: la artesanía. Al ser ésta un objeto producto del devenir del saber-hacer ancestral de su etnia, la decisión se enmarca dentro de la cultura autónoma ya que fueron ellos quienes empezaron a implementar esta mezcla en las artesanías. Por consiguiente, la introducción de un nuevo material implica adoptar y asimilar a sus saberes este elemento cultural ajeno, dando lugar a la cultura apropiada. Bonfil Batalla (1991) sostiene que:

"El uso de tales elementos culturales implican, en cada caso concreto, la asimilación y el desarrollo de ciertos conocimientos y habilidades para su manejo, la modificación de ciertas pautas de organización social y/o la incorporación de otras nuevas, el reajuste de aspectos simbólicos y emotivos que permita el manejo subjetivo del elemento apropiado, etcétera; son esos cambios en la cultura autónoma los que hacen posible la formación de un campo de cultura apropiada" (p.175)

En contraparte, la comunidad foránea que aporta sus técnicas autóctonas a la etnia Zenú, también participa en esta conexión interétnica como cultura autónoma, ya que para mantener y afianzar esta relación con fines comerciales, han modificado su gama de productos incorporando nuevos formatos o nuevos tamaños que les faciliten la elaboración a los zenúes. Estas modificaciones atienden a las necesidades de implementación de la variedades de productos con diversos tamaños, como bolsos, billeteras, portavasos, etc. los cuales necesitan un formato donde se pueda apreciar el diseño y no generar tantos desperdicios de material. El artesano Jhon Jersy Pérez manifiesta que el tejido mola viene en el tamaño preciso para que ellos los implementen en un bolso. Los Emberas han adaptado sus diseños tanto geométricos como de animales a diversos formatos para que en el corte no se afecte el diseño. "Más que todo se está utilizando acá en los bolsos es puro laberinto, ya que el laberinto se puede mochar como sea. Y ahora vino una mola pequeña que yo digo 
que la hicieron para acá. Es una mola de esas que tiene como 20 [centímetros], 18 por 14 [centímetros] ya viene directica para un bolso, tiene un ave, tiene un pescaito, tiene cangrejo (...) Esa mola viene directamente para un bolso ya la están haciendo directica solamente para acá". J. Pérez (en comunicación personal, 09 de agosto, 2016)

De igual manera sucede con la palma de iraca, sus artesanos la tejen en tamaño de individual, para que otros puedan utilizarla en diferentes productos. "La iraca yo la compro por individuales, como esos que le colocan a las mesas, a los juegos de comedor. Entonces yo lo compro por paquetes de seis individuales". M. Medina (en comunicación personal, 01 de agosto, 2016)

En estas relaciones interétnicas no se recriminan o prevalecen unos elementos culturales sobre otros, o se imparten decisiones por parte de agentes externos al grupo. Por el contrario, este contacto que da lugar a la mezcla de técnicas son el resultado de procesos consensuados entre los mismos artesanos, y son ellos quienes toman las decisiones. Lo loable, es que en este caso particular ambas comunidades se apoyan para permanecer activos en el mercado a través de su saber ancestral: el oficio artesanal. Esto demuestra que son los principales hacedores de este oficio quienes deben encauzar y determinar hacia dónde debe ir su producción.

\section{Análisis de composición morfológica: Formas y materiales}

A fin de analizar los elementos que caracterizan la composición morfológica y conceptualización a la producción de las artesanías combinadas en técnicas originarias, se escogieron algunas fotografías de productos que han sido elaboradas por algunos artesanos entrevistados. El estudio se realiza de acuerdo a sus variantes estéticas, como son: su forma, composición, combinación de material, tipología de producto (línea marroquinería, línea de decoración de hogar). Estas variantes fueron documentadas por producto, en una tabla diseñada para comparar las formas de integración de las distintas texturas, y definir si existen similitudes o diferencias de acuerdo a la tipología de la artesanía.

A partir de estos objetos seleccionados dentro del universo de piezas artesanales que conforman la producción artesanal Zenú, se pueden extraer diversas observaciones a nivel conceptual de estos productos, con el fin de analizarlas desde la dimensión del diseño. Es así, que en primera instancia, en cuanto a la morfología de las piezas, se puede identificar una tendencia hacia formas y estructuras geométricas: cuadradas, rectangulares, y algunas circulares, que marcan fuertemente la composición general del producto. En cuanto a la incorporación de una técnica foránea, algunos productos no son congruentes en llevar una composición clara y definida. Es decir, si la forma externa de la pieza es cónica o en forma de "v", la otra técnica incorpora en un formato cuadrado que rompe con la morfología general del producto, generando una visual que no favorece a su diseño. En esta línea se encuentra la apreciación del diseñador Rafael Barreto, quien sostiene que a pesar de que la mezcla de técnicas artesanales de distintas comunidades es consecuencia de esfuerzos de los artesanos por tener algo nuevo que ofrecer, estas artesanías, en su mayoría, son modelos que se encuentran muy distantes para considerarlos como productos con buen nivel de diseño. 
Barrera y Quiñones (2006) sostiene que la dinámica industrial ha sumergido a los artesanos en distintas situaciones que para ellos son nuevas y totalmente desconocidas, a tal punto que algunas de sus propuestas difieren con las demandas que establece el mercado. Esto es, por supuesto, resultado de un desconocimiento acerca de quién quiere artesanías, cómo las consume, dónde las compra, por qué las adquieren; respuestas que, según la autora, son determinantes de diseño. Citando a Hernán Lozano, quien participó en el primer seminario de diseño artesanal en Colombia, la autora valora al diseño:

"como un mecanismo de comunicación, de trabajo en equipo, en donde el conocedor de las nuevas determinantes de diseño, el diseñador de nuestra sociedad industrial y sólo él, las pueda comunicar al artesano, quien las pueda interpretar y conjugar con sus propias determinantes, para desarrollar el producto que quiere esa sociedad" (Lozano en Barrera y Quiñones, 2006:36)

Tal comunicación o traducción que puede realizar un diseñador se materializa en la orientación a nivel de composición de estos productos artesanales. En esta línea, los profesionales en diseño entrevistados, destacan una apreciación relevante en cuanto a este tema. Para Rafael Barreto, diseñador que trabajó con la etnia Zenú, ha visto este tipo de artesanías combinadas, y manifiesta que observando la pieza, se puede establecer que ambas técnicas han sido sobrepuestas, y no fue pensada otra manera más innovadora para integrarlas, hecho que evidencia poca conceptualización de los productos. En este sentido, se hace necesario el apoyo del diseñador, ya que los artesanos se enfrentan a áreas complejas y poco conocidas para ellos, como lo es el mercado. Es allí donde el diseñador debe ser un puente comunicativo entre el consumidor y el artesano, donde el primero manifieste sus deseos para luego ser traducidos y comunicados al segundo. (Barrera y Quiñones, 2006:37)

Retomando las apreciaciones alrededor de la integración de técnicas artesanas, la mezcla entre ellas se realiza colocando una sobre la otra, método que aplica para todos los productos, sea para línea hogar, o línea de marroquinería. Sin embargo, la unión entre las distintas texturas difiere por cada línea de productos. De acuerdo a la documentación realizada, se puede establecer que para la línea de productos para el hogar, la unión entre fibras se realiza a través de un pegamento especial, usado normalmente para el calzado. Por su parte, la línea de marroquinería, la unión se hace a través de la costura.

Otro dato relevante, son las razones por las cuales una técnica artesanal prevalece sobre la otra. Lo interesante, son los diversos motivos que justifican el porcentaje de prevalencia, los cuales van desde el regionalismo, hasta la estructura del producto y los costos que implican. En cuanto a la parte constructiva y estructural de la pieza artesanal, Reine Mendoza y Maribel Medina, manifiestan que la caña flecha da más consistencia y el producto queda más firme y visualmente más estético, frente a otro que esté hecho en su mayor parte de otra técnica o fibra. No obstante, si bien la caña flecha es un tejido que da rigidez y estructura a la pieza artesanal, para el artesano Jhon Jersy Pérez, la prevalencia de una técnica la establece su cliente de acuerdo a sus recursos económicos y al precio final que esté dispuesto a pagar, ya que de acuerdo a su presupuesto depende qué material va a prevalecer. Si el caso es de un cliente con poco presupuesto, la caña flecha es la que menos va a prevalecer, porque es más costosa. 
En definitiva, la creación y la continua producción de artesanías combinadas en técnicas artesanales de distintas comunidades fue un suceso y es una vigencia que se dio por decisión de sus mismos hacedores. No en vano, las modificaciones, como la adaptación de nuevos formatos de las técnicas foráneas a los productos zenúes, son respuestas de las comunidades vecinas en ampliar su mercado ofreciendo sus saberes ancestrales no como productos, sino como insumos. Estas decisiones de ambas comunidades indígenas se realizan bajo las nociones de control cultural expuestas por Bonfil Batalla (1991), las cuales claramente luchan dentro del campo artesanal por un capital simbólico: la prevalencia en el mercado, la cual se traduce en el sustento del núcleo familiar.

\section{Conclusiones}

El objetivo de este artículo consistió en analizar la producción artesanal Zenú y su derivación a la elaboración de piezas combinadas en técnicas artesanales de distintas comunidades originarias. Este abordaje apuntó a integrar instancias sociales, culturales, económicas y comerciales que dinamizan su producción, cuyos efectos se derivan en transformaciones que responden a las demandas permanentemente cambiantes por el mercado. Es en este punto donde radican los mayores aportes de este trabajo, ya que a través de esta situación presente en las artesanías Zenú, se indentificaron cómo las dimensiones sociales y económicas son el constructo dinámico responsable de las modificaciones artesanales. Dichas transformaciones se pueden analizar desde el ámbito del diseño porque se fundamentan en términos de innovación y de desarrollo de nuevos productos, lo que demuestra la inclinación en utilizar a esta disciplina como una herramienta que apoye a conseguir tal finalidad.

Asimismo, se identificaron tres principales motores que propician las transformaciones y las diversas estrategias artesanales: el dinamismo cultural, la lucha por el capital simbólico que responde a la tensión por la permanencia en el mercado, y al empeño constante de ofrecer nuevos productos. Es así como la articulación de estos aspectos favorece las eventuales confluencias de distintas culturas, generando mayores posibilidades de establecer relaciones comerciales y lograr la prevalencia en el mercado del sector artesanal. De allí, se hace imperativa la búsqueda de un componente innovador que conciba nuevas propuestas de artesanías, cuyos resultados pueden consistir en la mezcla de técnicas originarias en una pieza artesanal. Es en este caso muy particular donde se refleja dos grupos distintos que, desde su propio campo, cimientan en la imparcialidad estrategias perfiladas hacia una garantía de prevalencia mercantil.

De acuerdo a lo anterior, las particularidades que se presenten en las producciones artesanales, que en este trabajo se tomó como ejemplo la mezcla de técnicas de las artesanías Zenú, son consideradas variaciones productivas que responden a una yuxtaposición de distintos factores fundamentales que condicionan un contexto específico. En efecto, los zenúes demuestran cómo la diversidad cultural y la cohesión social son utilizadas como alternativas de desarrollo y como estrategias comerciales, que se materializan en el diseño de nuevos productos. Es así que se confirma que la producción Zenú de artesanías combinada es impulsada y valorada por sus artesanos como una nueva estrategia comercial que les permita ampliar su período de prevalencia en el mercado. 


\section{Lista de referencias bibliográficas}

Alavez, A. (2014). Interculturalidad: Conceptos, alcances y derechos. México: Ediciones GPPRD

Appadurai, A. (1991). La vida social de las cosas. Perspectiva cultural de las mercancías. México: Editorial Grijalbo.

Barrera Gloria; Quiñones A. (2006). Conspirando con los artesanos. Crítica y propuesta al diseño en la artesanía. Bogotá: Editorial Pontificia Universidad Javeriana

Barth, F. (1976). Los grupos étnicos y sus fronteras. La organización social de las diferencias culturales. México: Fondo de cultura económica.

Bayardo, R. y Lacarrieu, M.. (1997). Globalización e Identidad cultural. Buenos Aires: Ediciones Ciccus.

Beckett, J. (1988). Past and presente. the construction of aboriginality. Canberra, Aboriginal Studies Press, 1-10.

Benedetti, C. (2014). La diversidad como recurso. Producción artesanal Chané destinada a la comercialización e identidad. Buenos Aires: Editorial Antropofagia.

Bonfil, G. (1991). La teoría del control cultural en el estudio de procesos étnicos. Estudios sobre las Culturas Contemporáneas, 165-204.

Cultura Zenú o Sinú (2011). Recuperado de: http://www.historiacultural.com/2011/12/ cultura-zenu-sinu.html

García Canclini, N. (1995). Consumidores y Ciudadanos: conflictos multiculturales de la globalización. México: Editorial Grijalbo.

Jackson, J. (1995). Cultura genuina y espúrea: las políticas de la indianidad en la región del Vaupés, Colombia. American Ethnologist. The Journal of the American Ethnological Society, 22(1): 3-27

Larraín, A. (2014). Los indígenas Zenú y la educación propia. Entre la "ausencia" de una lengua tradicional y la reivindicación de otros marcadores étnicos. Revista Digital do Instituto Latino-Americano de Arte, Cultura e História, 3, 1-17.

Ledesma, C. (2005). Nuevos principios y fundamentos del diseño internacional e intercultural. Buenos Aires: Editorial Osmar D. Buyatti

Monserrate, R.; Serrano, D. (2016). Diagnóstico del sector artesanal y las particularidades regionales en Colombia, artesanías en barro de Chamba, filigrana y caña flecha". Estadística e información Artesanías de Colombia

Rotman, M.; Radovich, J. C.; Balazote, A. (2007). Pueblos originarios y problemática artesanal: Procesos productivos y de comercialización en agrupaciones Mapuches, Guaraní/Chané, Wichis, Qom/Tobas y Mocovíes. Córdoba: Centro de Estudios Avanzado

\footnotetext{
Abstract: In the field of craft production, there are many researches and studies in reference to handicrafts and their production modality in the different communities. The handcraft has been studied under diverse perspectives, from the anthropological, from its productive modality, from its structuring and division of work within the family nucleus, from the innovations of its techniques, to its commercialization. This paper studies the handicraft pro-
} 
duction from the perspective of cultural flows and the constant dynamism of the present and its influence on the new crafts, specifically those that are combined with other original techniques of different craft communities. This new type of handicrafts emerged recently in Colombia, under the ethnic Zenú's hands in the department of Córdoba, but its appearance was gradual. The conditions that favored its elaboration, needs to be studied and evaluated from the perspective of the different actors active in the handcraft field; considering the intangible qualities that bring traditional aspects and cultural values to production.

The analysis of these considerations, understood as part of dynamic social processes, is investigate from the perspective of the development of handicrafts, how the different technical innovations, the new demands arising in modern times and their positioning in the market, lead to new commercial strategies and new crafts productions combined with techniques from different craft communities.

Keywords: Social field - native peoples - handicraft production - design cultural identity - artisanal marketing

Resumo: No campo da produção artesanal, existem muitas pesquisas e estudos referentes ao artesanato e sua modalidade de produção nas diferentes comunidades. O artesanato tem sido estudado sob diversas perspectivas, desde a antropológica, desde a sua modalidade produtiva, desde a estruturação e divisão do trabalho dentro do núcleo familiar, desde as inovações de suas técnicas até a sua comercialização. Este artigo estuda sobre a produção artesanal a partir da perspectiva dos fluxos culturais e do constante dinamismo do presente e sua influência sobre os novos ofícios, especificamente aqueles que são combinados com outras técnicas originais de diferentes comunidades artesanais. Este novo tipo de artesanato emergiu recentemente na Colômbia, sob as mãos da etnia Zenú, no departamento de Córdoba, mas sua aparência foi gradual. As condições que favoreceram sua elaboração precisam ser estudadas e avaliadas sob a perspectiva dos diferentes atores ativos no campo artesanal; considerando as qualidades intangíveis que trazem aspectos tradicionais e valores culturais para a produção. A análise dessas considerações, entendidas como parte de processos sociais dinâmicos, é investigada a partir da perspectiva da o desenvolvimento do artesanato, como as diferentes inovações técnicas, as novas demandas surgidas nos tempos modernos e seu posicionamento no mercado levam a novas estratégias comerciais e novas produções artesanais aliadas a técnicas de diferentes comunidades artesanais.

Palavras chave: Campo social - povos indígenas - produção artesanal - design - identidade cultural - marketing artesanal.

[Las traducciones de los abstracts fueron supervisadas por el autor de cada artículo] 